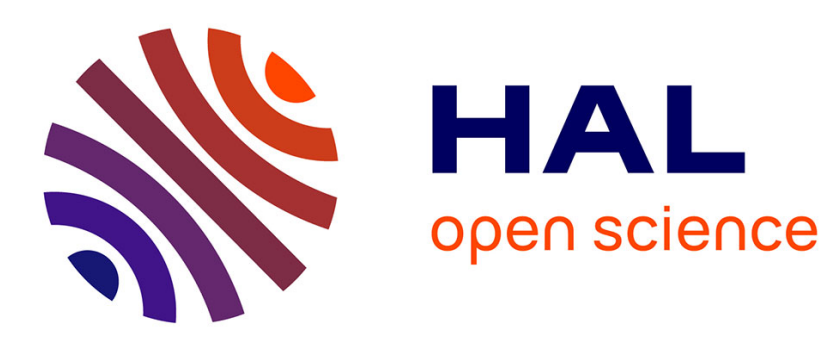

\title{
An analysis of the impact of larger aircraft (A-380) on flight frequency
}

\author{
Aliya Ussinova, Isabelle Laplace, Chantal Roucolle
}

\section{To cite this version:}

Aliya Ussinova, Isabelle Laplace, Chantal Roucolle. An analysis of the impact of larger aircraft (A380) on flight frequency. Energy efficiency, 2018, 11 (3), pp.701-712. 10.1007/s12053-017-9591-7 . hal-01682632

\section{HAL Id: hal-01682632 https://hal.science/hal-01682632}

Submitted on 26 Jan 2018

HAL is a multi-disciplinary open access archive for the deposit and dissemination of scientific research documents, whether they are published or not. The documents may come from teaching and research institutions in France or abroad, or from public or private research centers.
L'archive ouverte pluridisciplinaire HAL, est destinée au dépôt et à la diffusion de documents scientifiques de niveau recherche, publiés ou non, émanant des établissements d'enseignement et de recherche français ou étrangers, des laboratoires publics ou privés. 


\title{
An Analysis of the Impact of Larger Aircraft (A-380) on Flight Frequency
}

\author{
Aliya Ussinova \\ Toulouse School of Economics \\ aussinova@gmail.com \\ Tel:+33 (0)7 81512565 \\ ORCID : 0000-0002-0175-4459
}

\author{
Isabelle Laplace \\ Ecole Nationale de l'Aviation Civile \\ isabelle.laplace@enac.fr \\ Tel: +33 (0)5 62259542 \\ ORCID: 0000-0001-8044-2148
}

\author{
ChantalRoucolle \\ Ecole Nationale de l'Aviation Civile \\ chantal. latge-roucolle@enac.fr \\ Tel:+33 (0)5 62259531 \\ ORCID : 0000-0002-3075-7376
}

\begin{abstract}
Innovations in the airline industry can have a significant impact on the behavior of air transport stakeholders: airline companies, airports and passengers. In this paper, we consider the introduction of a double-deck plane, the A-380, which is currently the largest aircraft available. Due to its size, it is able to carry at once approximately twice as many passengers as any other medium-sized aircraft. When associated with a reduction in flight frequencies, the operation of such aircraft is expected to lower the environmental impact. However, flight frequency depends on factors others than the aircraft size, such as airport fees, demand and strategic decisions of companies to maximize their profits under competition. Using a monthly panel data set on airlines' supply over 10 years, on 118 routes, we test if the use of the A-380 impacts airlines' flight frequency at a route-level. Results suggest that heavy use of the A-380 leads airlines to reduce their own flight frequency. We also find that when facing the introduction of the A-380 on a route, airlines will tend to react by increasing their own flight frequency.

Index terms - A-380, flight frequency, airline innovation, airline competition
\end{abstract}

\section{Acknowledgements}

The authors thank Cyril Allignol and Nicolas Peteilh at ENAC for their help in getting aircraft fuel consumption estimations. They thank Steve Lawford at ENAC for his useful comments. They also thank their reviewers Milan Scasny and Anna Alberini for their constructive and useful comments on this paper. 


\section{Introduction}

The air transport market is characterized by numerous interactions between airlines, passengers, service providers, official regulators, and countries. Given this complex system, increasing traffic flows, and the global appetite for sustainable development, the airline market must find strategies to achieve operational efficiency and maintain high profits under competitive pressure. On the other hand, aircraft manufacturers must address these issues by providing innovative solutions for future aircraft. Their solutions will impact airlines as well as the other participants of the air transport system. One example is the launch of the biggest passenger double-deck aircraft: the A-380. This paper contributes to the understanding of air stakeholders' behavior given an innovation. Our main objective is to identify whether there is a decrease in route level flight frequencies after the introduction of the A380 , due to higher capacity of airplane, which allows for better operational efficiency and a lower carbon footprint. The flight frequency is defined as the total number of monthly flights between departure and destination points supplied by an airline company. To answer this question we first summarize existing studies, and then describe the available data. The fourth part is dedicated to a comparison of the emission rates of the A-380 and competing long-haul aircraft. In the fifth and sixth sections we present the econometric model and analyze the results.

\section{Literature review}

In 2013, air transport activities contributed to $12 \%$ of total transport and $2 \%$ of world $\mathrm{CO}_{2}$ emissions (Wei, Cui, and Gil 2016). With rising global environmental concerns and volatile oil prices, aircraft manufacturers must develop innovative technologies and adjust their operational efficiency. The A-380 is the largest aircraft used for commercial aviation. Due to economies of size, it is expected to reduce fuel burn per passenger, when taking into account the classic seat configuration provided by the manufacturer (King 2007). In his analysis of the A-380 King (2007) highlights that the aircraft suits long-haul and high-density markets, allowing them to absorb highfrequency operations. The author notes that intelligent use of the aircraft can sustain markets during high fuel price periods by reducing the fuel cost per passenger-kilometer. The frequency reduction leads directly to lower fuel burn and as a consequence to lower levels of carbon emission.

If air carriers introduce the A-380 in their fleet does this lead to a lower flight frequency on the routes?

We analyze existing studies that address the behavior of the aviation sector under environmental constraints and innovation. These studies introduce the following ideas:

1. The strategic theoretical approach to innovation and competition;

2. The influence of aircraft type and size on fuel consumption and $\mathrm{CO}_{2}$ emissions;

3. The current fuel and operational efficiency of airline companies

Addressing the first point Aghion, Bloom, et al. (2002) shows that on duopoly markets, the probability to follow innovation should be higher for routes with neck-and-neck competition, i.e. when firms operate at the same technological level. In other words, in duopoly, as competition pressures prices and margins, firms have incentives to innovate to become the leader of the market (this is called the "Escape Competition Effect"). Only laggard firms (i.e. firms with a low market power) in unleveled sectors (i.e. when there are leader and laggard firms on the market) would tend to have less incentives to innovate when the competition increases on the market. Aghion, Bechtold, et al. (2014) shows that "increased competition decreases the post-innovation rents of laggard firms, and thus their incentive to catch up with the leader".

However, in air transport the theory of laggards does not seem to be verified, at least for one of the main disruptive innovations made by laggard airlines when creating the low-cost business model (Abeyratne 2015). In Europe, Ryanair (founded in 1985), was initially a full-service conventional airline with two cabin classes and three different types of aircraft under lease. Ryanair disrupted the European air transport market, until then dominated by legacy airlines, by becoming a low-fare airline operating frequent point-to-point flights on short-haul routes from regional and secondary airports. In the US, Southwest Airlines not only disrupted the US air transport market, but also the road transport market by competing aggressively against bus transport in Texas (Abeyratne 2015).

Besides the development of low-cost carriers another illustration of disruptive innovation in air transport is the introduction of the A-380 aircraft. This was the first time that such a large aircraft was operated. The main disruptive innovation of the A-380 is therefore linked to its size.

Among all the aircraft characteristics, aircraft size may be the one which has the biggest impact on the entire aviation industry. Airlines choose the size of the aircraft in their fleet in order to provide the most appropriate air transport capacity given competition. Airport planners need to know the size of the aircraft for both technical 
(runways, gates etc.) and practical (congestion) reasons. Policy makers use the predicted aircraft size for planning expensive infrastructure investments and future traffic control regulation.

Scotti and Volta (2015), Park and O'Kelly (2014), Morrell (2009), Miyoshi and Mason (2009) focus on the relationship between aircraft size and environmental productivity, arriving at conclusion that larger aircraft provide efficiency improvement and that there is an overall trend towards larger aircraft types for short and medium haul flights. These articles provided grounds for baseline assumption on the efficiency of larger aircraft.

Pagovi and Psaraki-Kalouptsidi (2016) come up with creative instruments to tackle endogeneity between market share (measure of concentration of the market) and frequency. These are market-related instruments (number of airlines on the market, number of offered connections), a route-level instrument (if the airport is a hub for the operating airline) and rival-related instruments (percentage of non-stop rival routes). In our specification, we will test if the number of airlines characterizes the market concentration, since other measures such as Herfindahl-Hirschman Index (HHI), calculated by summing the squared market shares, does not vary sufficiently over time.

While studying the fuel emission some authors take a company-specific or an industry approach. Others consider the effect on passenger demand. Wei, Cui, and Gil (2016) identify that pressure from competitors and strict governmental regulations are the driving forces for innovation in the airline industry. They study how environmental innovations affect the companies financial and operational performance.

Airline efficiency is also linked to the way they accommodate their air transport capacity to existing and future demand. Airlines may use two levers: aircraft size and service frequency. Both variables play a central role in their profitability (by the load factor) and strategic (competition) decisions. Keeping high load factors, while offering high frequency, moves airlines towards the use of smaller aircraft. In 2006, according to Givoni and Rietvel (2009), "at many of the world's largest airports there were fewer than 100 passengers per air transport movement despite growing congestion and delays". Givoni and Rietveld (2009) associate this choice with the benefits of high frequency service, the competitive environment in which airlines operate and the way airport capacity is allocated and priced. By a regression analysis of over 500 routes in the US, Europe and Asia, they provide empirical evidence that the choice of aircraft size is mainly influenced by route and airport characteristics. They estimate that the aircraft size depends on market size, with an elasticity of 0.35 , indicating that carriers give priority to increases in frequency.

Other authors Pai (2010), Wang et al. (2010) and Bilotkach (2014) examine the frequency strategies and aircraft sizes. Wang et al. (2010) found that in emerging markets airlines adjust for higher traffic by increasing frequency. They also concluded that more concentrated ${ }^{1}$ market structures resulting from mergers lead to reduction in frequencies. Babic, Kuljanin, and Kalic (2014) note that efficiency is an important factor that impacts market share; by increasing market share, airline companies have a higher probability of profit maximization. There are two strategies that airlines can follow: increase frequency or increase seating capacity through larger airplanes. The literature demonstrates that airline companies have to adopt efficient strategies to sustain their competitiveness under the conditions of a volatile and dynamic market.

\section{Data}

The database used to analyze the flights frequency is constructed from the OAG Schedule Analyzer (a database of the Official Airline Guide) ${ }^{2}$. It contains past, current and future information on supplied scheduled flights. First published in 1929, the OAG today holds information on 1,000 airlines and 4,000 airports. The advantage of Schedule Analyzer is that it allows us to view the activities of competitors on different routes and obtain information on the relative share of supply. It contains variables such as airports, carriers, flight frequencies, aircraft family types and alliances. This is one of the most comprehensive and widely used datasets on traffic flow.

We also use the ENAC Database on Air Transport, which contains information on 500 airline companies and consists of three separate databases on Airline Companies, Airports and Traffic Flows, based on data from various sources including IATA ${ }^{3}$, ICAO ${ }^{4}$ and Airline Monitor. The ENAC database was used to extract the actual recorded traffic flow on the routes, which represents the demand proxy in our model.

The data has a panel structure. Besides having cross-sectional and time-series dimensions, the dataset on airline frequency and corresponding covariates has a more complex hierarchical form (Baltagi 2008): the dependent variable $y$ measures the flight frequency for airline $i$ on origin-destination route $j$ at a month $t$. By capturing effect between individuals and their behavior over time, we are able to ignore the impact of omitted variables that are constant over time: these are the company or route-specific characteristics that are not observable. The time-series dimension of panel data captures the dynamics of development. Market entrance, merger and exit are common

\footnotetext{
1 "More concentrated" refers to the concentration in terms of HHI (close to 1), when there are fewer carriers

${ }^{2}$ OAG Official Website: http://www.oag.com/

${ }^{3}$ IATA Official Website: http://www.iata.org/

${ }^{4}$ ICAO Official Website: http://www.icao.int/
} 
practices in airline industry. We are then able to control for the highly dynamic and rapidly changing competitive structure of the market.

Aside the benefits of panel structure, there are potential issues that could lead to biased estimation of the coefficients of our regression models. Time-series data often exhibit seasonal behavior (Baltagi 2008), which is also the case for the airline market. Depending on the route, there are particular periods when passenger traffic increases substantially due to vacation, business seasons, etc. Figure 1 shows that seasonality is a common feature for airline market.

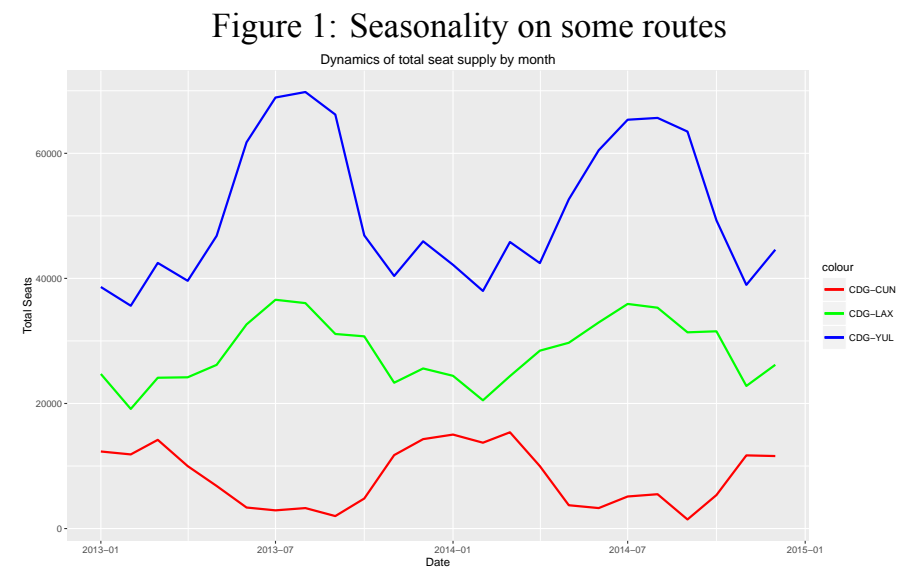

There is a clear seasonal trend, but the pattern is not the same ${ }^{5}$. For the CDG-LAX (Charles de Gaulle - Los Angeles Airports) and the CDG-YUL (Charles de Gaulle - Montréal Airports) routes, we see that seats surge dramatically in summer periods with peaks in July-August, whereas for the CDG-CUN (Charles de Gaulle - Cancun Airports) the highest points occur in December and January. This is not surprising, as people travel from Paris to Los Angeles and Montréal in the summer, whereas the Paris-Mexico route is a tourist destination in the winter months. In our sample routes have a similar seasonality pattern. Seasonality will be controlled in this study by introducing monthly dummy variables (Baltagi 2008).

Overall, there is an annual increase in passenger traffic, as shown in Figure 2:

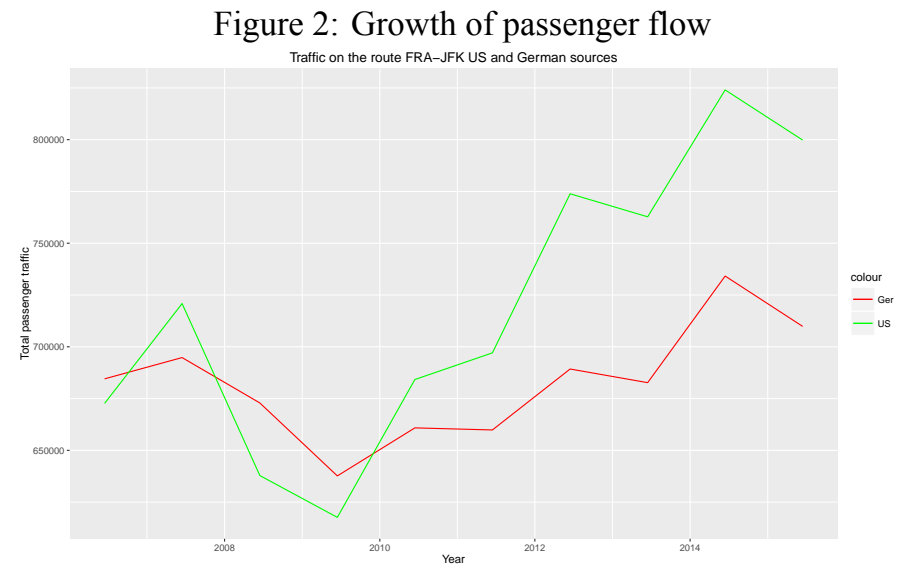

Despite the shock from 2007 to 2009 due to the global financial crisis, there is an upward trend. We will therefore, in our model, control for special events and shocks using dummy variables for the years 2008, 2009 and 2010 .

In total there are 151 routes on which the A-380 aircraft operates. We observe the data on a monthly basis. Due to its size, the A-380 is designed for long-haul routes with high demand. A long-haul route (Park and O'Kelly 2014 ) is considered to be a non-stop flight with distance greater than 2,000 km. Only routes that correspond to the definition of long-haul routes are kept, and 30 routes with distance less than 2,000 km were removed from our dataset. The airlines on these 30 routes did not use the A-380 on a regular basis: these were rather exceptional cases, which could potentially be for airlines' experimental purposes. We also remove 3 routes on which we miss

\footnotetext{
${ }^{5}$ The blue line corresponds to the airport pair of Paris-Montréal, the green line is Paris-Los Angeles, the red line is Paris-Cancun.
} 
some data and observe the data monthly for the last 10 years on 118 routes, giving $\mathrm{N}=30,905$ observations. Some descriptive statistics of the dataset are presented in Table 1.

Table 1: Descriptive Statistics of variables

$\begin{array}{lcccc}\text { Statistic } & \text { Mean } & \text { St. Dev. } & \text { Min } & \text { Max } \\ \text { Distance in km } & 6,147.7 & 3,090.9 & 1,985 & 13,802 \\ \text { Flight frequency } & 54.7 & 51.9 & 1 & 548 \\ \text { Log of population } & 15.3 & 1.1 & 12.9 & 17.5 \\ \text { Number of companies } & 4.3 & 2.9 & 1 & 17 \\ \text { Ratio of weight A-380 } & 0.086 & 0.242 & 0.000 & 0.983 \\ \text { Competitors' ratio of weight A-380 } & 0.084 & 0.197 & 0.000 & 0.975 \\ \text { Log of annual traffic* } & 13.5 & 0.8 & 1.1 & 15.231\end{array}$

Notes: $\mathrm{N}=30,905$

The mean distance of the route is $6,147 \mathrm{~km}$. The average frequency per airline serving the route is 54 flights per month. On average there are 4 competitors on the route; however, there are routes that are entirely supplied by a single carrier.

In this specification we are interested in two proxies for demand: logarithm of population and annual route traffic. The former is collected from the World Bank database while the latter is collected from the ENAC Database. However, yearly traffic data is available for only 118 out of the total 121 long-haul routes, on which the A-380 operates.

\section{Comparison of emission rates of the A-380 and competing long-haul aircraft}

Prior to the analysis of the effect of the size on the frequency, this section is dedicated to a descriptive analysis of the fuel consumption per seat given the standard seat-configuration for the A-380 and competing wide-body long-haul aircraft. Fuel consumption is proportional to emission levels. The higher the level of fuel consumption per seat, the less efficient is the aircraft in terms of fuel emission.

The estimation of fuel consumption is based on BADA (Base of Aircraft Data), an Aircraft Performance Model which is a standard framework developed jointly by EUROCONTROL, aircraft manufacturers and airline companies. Based on a kinetic approach to the modeling of aircraft performance, this specification relies on two factors: the model specification that defines theoretical assumptions used for estimation of aircraft performance parameters; and the datasets, the individual parameters of aircraft used in estimations ${ }^{6}$. When simulating the performance of aircraft on the routes, we set the aircraft payload to its maximum level. So, the estimated fuel consumption is higher than in reality and accounts for the transportation of the fuel itself. Figure 3 contains a sample of 8 routes in the range of 1,800 to $7,700 \mathrm{~km}$. The bars represent the average fuel consumption per seat in kg by type of aircraft. Figure 3 depicts the non-linearity of fuel consumption with respect to distance, since the consumption of fuel varies depending on the phases of flight (taxi, take-off, cruise, descent and landing) as well as other factors such as altitude, direction and meteorological conditions, which are set equal in all simulations. As distance increases, the fuel efficiency per seat of the A-380 slightly improves in comparison to its main competitors. Nonetheless, the A-380 and B-747 are close in terms of fuel consumption per seat on the CDG-SFO (Paris-Charles de Gaulle - San Francisco international) and HKG-CDG (Hong-Kong International - Paris Charles de Gaulle) routes. On shorter routes, ATH-DXB (Athens International - Dubai International) and SIN-KIX (Singapore Changi International Kansai International), the A-380 burns more fuel than the B-737, B-767 and B-747 aircraft. The graph illustrates that the A-380 provides slight reductions in emission rates due to lower fuel consumption on longer distances and is less efficient on shorter distances.

\section{The Model}

A general model with individual effects is defined with the following specification:

$$
y_{i t}=\boldsymbol{x}_{\boldsymbol{i t}} \boldsymbol{\beta}+\alpha_{i}+\epsilon_{i t},
$$

\footnotetext{
${ }^{6}$ Airline Monitor Official Website (Base of Aircraft Data): http://www.eurocontrol.int/services/bada
} 

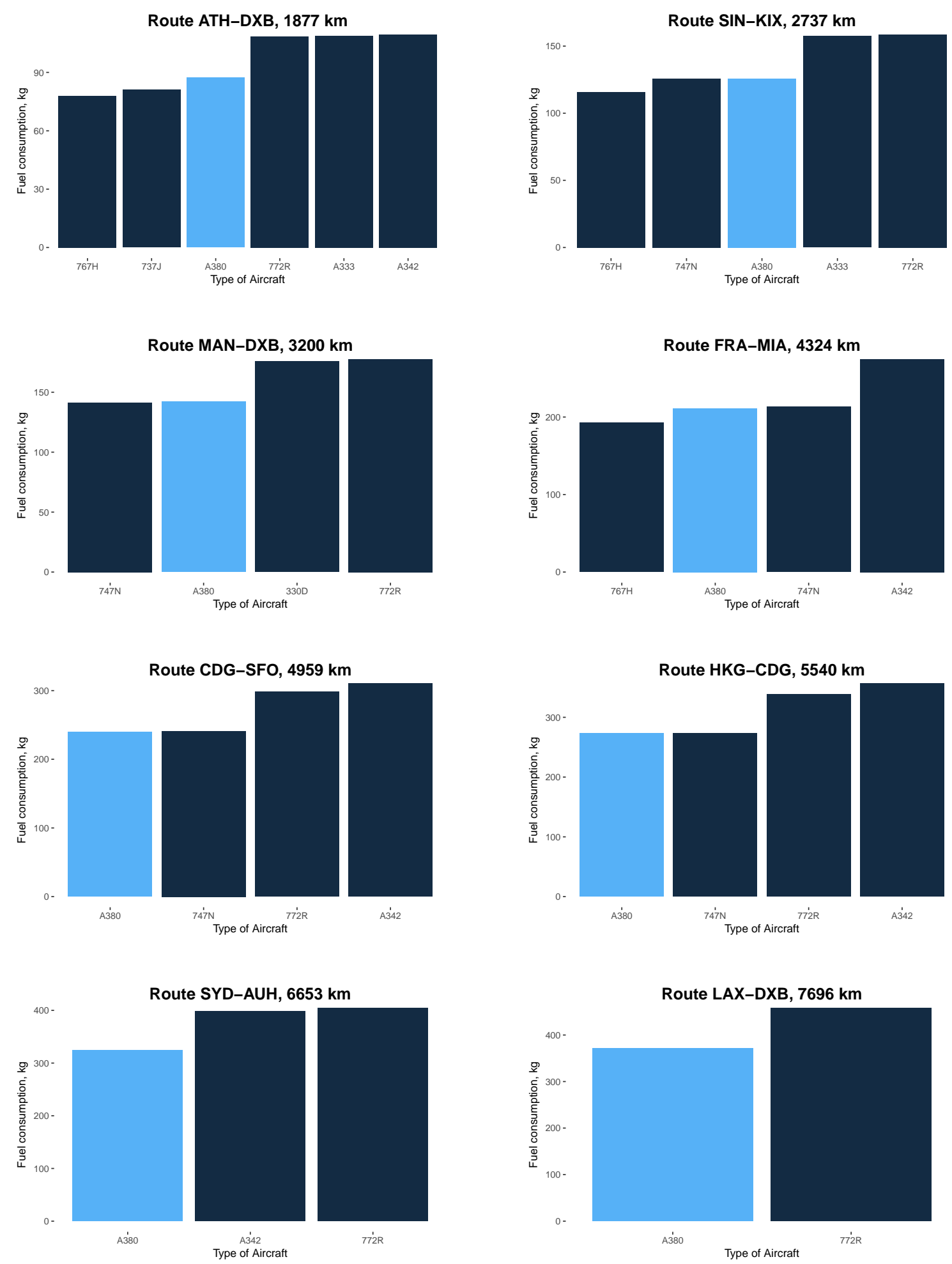

Figure 3: The average fuel consumption per seat in $\mathrm{kg}$ by type of aircraft. 
where $\alpha_{i}$ is individual unobserved heterogeneity and $\epsilon_{i t}$ is an idiosyncratic error. For technical details on panel estimation see (Wooldridge 2006). The model allows for time-invariant latent effects that are specific to route or airline company. Depending on the model specification $\alpha_{i}$ is interpreted as a random or fixed effect. Such types of models provide consistent estimation under the strict exogeneity condition, which restricts the effect of independent variables on $y_{i t}$ conditional on the unobserved effect $\alpha_{i}$ :

$$
E\left(y_{i t} \mid \boldsymbol{x}_{\boldsymbol{i} \mathbf{1}}, \boldsymbol{x}_{\boldsymbol{i} \mathbf{2}}, \ldots, \boldsymbol{x}_{\boldsymbol{i} \boldsymbol{T}}, \alpha_{i}\right)=\boldsymbol{x}_{\boldsymbol{i t}} \boldsymbol{\beta}+\alpha_{i}, \quad \forall t=1, \ldots, T .
$$

In terms of idiosyncratic errors this condition is equivalent to the following assumption:

$$
E\left(\epsilon_{i t} \mid \boldsymbol{x}_{\boldsymbol{i 1}}, \boldsymbol{x}_{\boldsymbol{i} \mathbf{2}}, \ldots, \boldsymbol{x}_{\boldsymbol{i} \boldsymbol{T}}, \alpha_{i}\right)=0, \quad \forall t=1, \ldots, T \text {. }
$$

The assumption of strict exogeneity states that the error term is uncorrelated with all past, present, and future $x$ 's, conditional on the fixed effect. If this assumption does not hold, the usual methods to deal with panel data cannot by applied. The fixed effect model with unobserved heterogeneity is one of the most popular approach for estimation of non-dynamic panel regressions, and will be a starting point for our statistical inference.

We use a reduced-form model to test the impact of innovation on flight frequency. The model encompasses both the effect of own use of the A-380 on the company's frequency and the effect of the use of A-380 by competitors on the route. We also introduce controls for other factors that might also impact flight frequency. The model is expressed as:

$$
\begin{aligned}
F R E Q_{i j t} & =\beta_{0}+\beta_{1} N U M B C O M P_{i t}+\beta_{2} P R O X Y D E M A N D_{i, t-1} \\
& +\beta_{3} D U M M Y U S E p o s A 380_{i j, t-1}+\beta_{4} D U M M Y U S E 100 p e r c A 380_{i j, t-1} \\
& +\beta_{5} C O M P R A T I O 380_{i j, t-1}+\beta_{6} D U M M Y 2008_{i j t}+\beta_{7} D U M M Y 2009_{i j t} \\
& +\beta_{8} D U M M Y 2010_{i j t}+\beta_{9} F E B_{i j t}+\beta_{10} M A R_{i j t}+\beta_{11} A P R_{i j t}+\beta_{12} M A Y_{i j t} \\
& +\beta_{13} J U N_{i j t}+\beta_{14} J U L_{i j t}+\beta_{15} A U G_{i j t}+\beta_{16} S E P_{i j t} \\
& +\beta_{17} O C T_{i j t}+\beta_{18} N O V_{i j t}+\beta_{19} D E C_{i j t}+\alpha_{i}+\epsilon_{i j t}
\end{aligned}
$$

where:

$F R E Q$ is the frequency of flights supplied by airline $j$ on route $i$ per month $t$.

$N U M B C O M P$ is the number of companies operating on route $i$ during period $t$. This variable is used to represent the level of competition on the market. Other conventional competition measurements, such as HHI, have also been tested but their effect were non significant.

PROXYDEMAND accounts for the total demand for airline services on the route. We consider two proxies: population and annual traffic on the considered route. These demand proxies are tested in two separate equations to analyze the robustness of the model. The population proxy is the one-period lagged logarithm of the average of countries' populations at the departure and arrival airport of the route $i$ per year. The other demand proxy is the one-period lagged logarithm of two-way annual traffic between airports. We find that changes in the independent variables do not have immediate effect on frequency. The current level of frequency is affected by past levels of demand; this is why the demand proxy is introduced with a one-period lagged. Moreover, the lagging of the variables might be helpful to capture possible endogeneity in the model.

DUMMYUSEpos A380 and DUMMYUSE100percA380 are one period lagged dummies capturing the intensity of utilization of the A-380 on route $i$ by airline $j$. Moreover, using a lagged and discrete variable, we avoid the issue of endogeneity between the level of flight frequency and the ratio of A-380 use. The intensity of use is calculated in terms of the total weight transported. DUMMYUSE100percA380 equals 1 if the airline uses exclusively the A-380 for its operations on the corresponding route during the previous period of time. The intensity of use in this case equals 100\%. DUMMYUSEpos A380 equals 1 if the airline uses the A-380 on the route for its operations during the previous period of time, but the use is not exclusive. In this case the ratio of use is positive but lower than $100 \%$. These two dummies allow us to distinguish flight frequency variations depending on the intensity of A-380 use during the previous period: when companies use only A-380 or when airlines, along with A-380, use other types of aircraft. The variation in frequency is measured in comparison to the reference situation where the airlines don't use the A-380 on the considered route during the previous period of time.

COMPRATIO380 is the intensity of utilization of the A-380 by competitors on the route with respect to other aircraft types. It is calculated as the ratio of total weight (seats and cargo converted to $\mathrm{kg}$ ) carried by the A-380 aircraft on the route to total weight carried by all types of aircraft. In our specifications we consider the lagged version of this variable.

Finally we use monthly fixed effects to control for potential seasonality. We introduce one dummy variable per month, $F E B$ to $D E C$, January being the month of reference. 
Because of the panel nature of the data, a number of tests are implemented to determine both the consistent model and the appropriate method of estimation. The Hausman test rejects the null assumption that the individualspecific effects are uncorrelated with the explanatory variables of the model. As a consequence we specify the model as a fixed effect model. ${ }^{7}$

The panel structure of the data should also lead to the presence of serial correlation. The definition of serial correlation is that the covariance between two error terms is not equal to zero: $\operatorname{Cov}\left(u_{i t}, u_{s t^{\prime}}\right) \neq 0, \forall i, s, t, t^{\prime}$. The presence of serial correlation in linear panel models leads the estimators to be no longer best linear unbiased estimators. This must be corrected to recover estimation efficiency. We use the Wooldridge test to confirm or reject serial correlation in our data. The p-value for Wooldridge test on fixed effect panel model is lower than 0.00001 on 413 airline companies operating on 118 routes with $F(1,409)=143.19$ or 142.26 depending on the demand proxy used. Therefore, there is strong evidence against $H_{0}: \operatorname{Cov}\left(u_{i t}, u_{s t^{\prime}}\right)=0$, in favor of alternative hypothesis, justifying the presence of serial correlation. Therefore, our next approach is to construct a model with serial correlation robust inference.

The Panel Corrected Standard Error (PCSE) method is implemented for the estimation, allowing us to control for serial correlation. We assume that the errors follow a AR(1) process. The estimated value of the $\rho$ coefficient, close to 1 , indicates a Durbin-Watson statistic for autocorrelation close to 2 , meaning that the most relevant estimation method for the model is the first-difference estimation.

\section{Results}

In Table 2 we present the results of the following models:

1. Fixed effect estimation with robust errors on 118 routes with logarithm of population as a demand proxy; number of observations is 30,905 .

2. Fixed effect estimation with robust errors on 118 routes with two-way annual traffic as a demand proxy; number of observations is 30,905 .

3. The first difference estimation to correct for serial correlation on 118 routes with logarithm of population as a demand proxy; number of observations is 30,391. The estimation was performed for first-differenced dependent and explanatory variables.

4. The first difference estimation to correct for serial correlation on 118 routes with two-way annual traffic as a demand proxy; number of observations is 30,391. The estimation was performed for first-differenced dependent and explanatory variables.

As mentioned above, the total number of routes, defined as long-haul routes (distance more than $2,000 \mathrm{~km}$ ) is 121 routes. However, there was available data on annual traffic, for only 118 out of 121 routes. Annual traffic and the logarithm of population are proxies for airline demand. These two proxies were tested to verify the robustness of the model. For comparison we provide the results of heteroskedasticity-robust fixed effect coefficients in columns 1 and 2 of Table 2. The third and fourth columns report serial-correlation corrected estimations using first-differencing on 118 routes with population and traffic on the route, respectively, as a proxy of demand.

As we can see from Table 2 there is a large difference in the value of the coefficients from fixed effect and first-differenced models. Nonetheless, in most of the cases the variables that are statistically significant under fixed effects are also significant under first differenced estimation. The fixed effect robust errors generally underestimate the actual variation of estimators and, should be interpreted with caution in the presence of significant serial correlation, as is the case here.

The coefficients of the first-differenced models have similar values, whatever demand proxy is used as the explanatory variable. This confirms the robustness of our model to the demand specification. Nonetheless, we can notice the insignificance of the traffic estimated parameter (column 4 of Table 2).

Our main interest is the statistical significance and signs of the estimated parameters: their significance allows us to determine if there is a response after the introduction of innovation; their signs indicate the direction of the change in airlines' behavior. The signs of the estimated coefficients in this model correspond to the theoretical expected results.

A higher number of companies increases the competition, leading to more frequent flights. Airlines increase their supply under increasing competitive pressure as they need to better match customers preferences to remain

\footnotetext{
${ }^{7}$ The Hausman test consists in testing the null assumption of independence between the individual-fixed effects and the exogenous variables of the model. In case of rejection of the null assumption the model is specified as a fixed effect model. The estimated p-value for the Hausman test is less than .001 with $\mathrm{t}$-statistic: $\mathrm{t}(18)=843.41$
} 
Table 2: Regression estimates

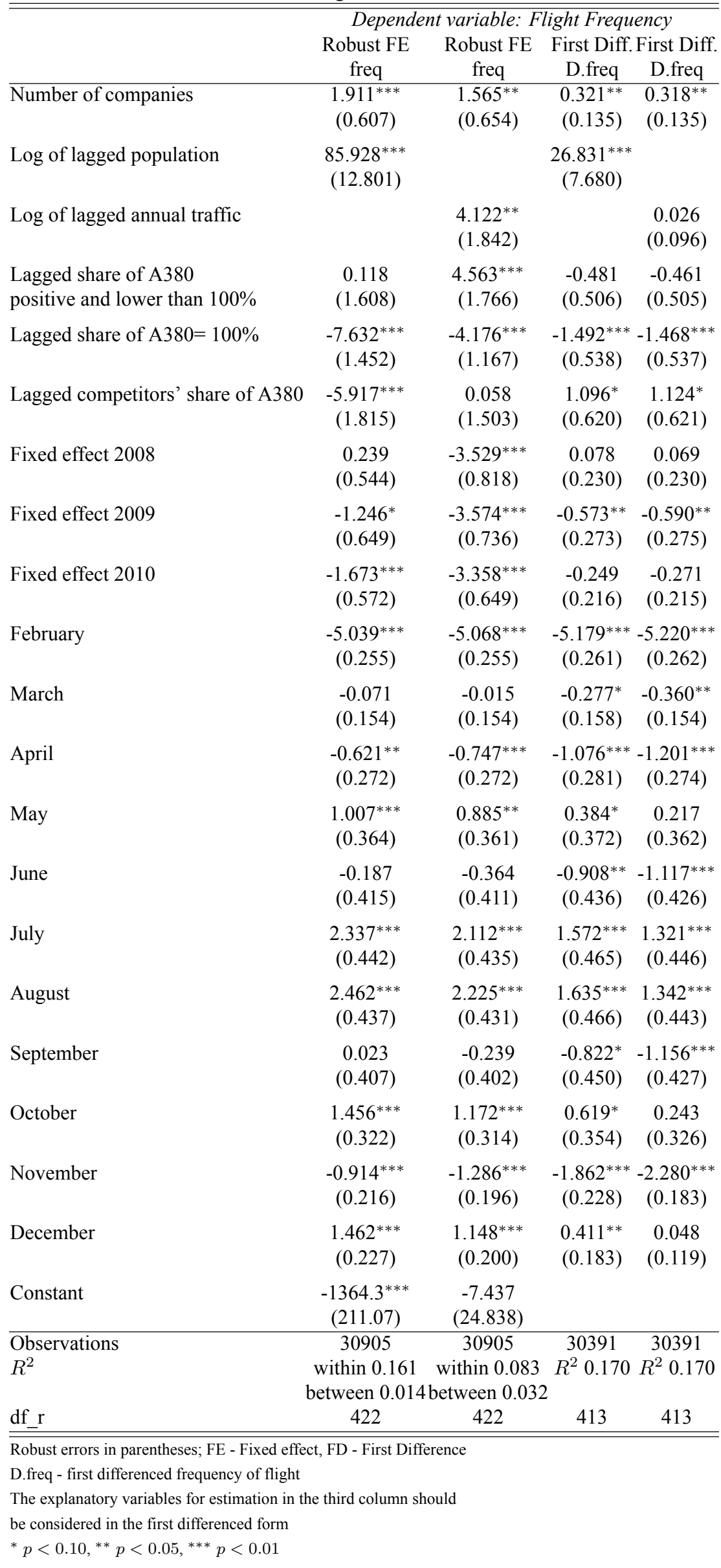


competitive. If there is an increase in the population or in traffic during the previous year, which corresponds to an increase in demand, then there is a positive impact on flight frequency. The higher is the demand, the more often airlines will schedule flights to catch this new demand. In the last specification we use annual traffic as a demand proxy. However, we do not find a statistically significant impact of this variable using the first-differenced specification (column 4 of Table 2) and conclude that population may be considered as a better proxy for demand. The main variables of interest are the lagged variables indicating the intensity of use of the A-380, the innovation, on the route. We test the adaptation to innovation, in terms of flight frequency, when the innovation comes from competitors on the routes and when the airline itself is innovating.

When considering own innovation, the estimated coefficient is statistically significant and negative in the case of $100 \%$ use of the A-380 on the route during the previous period. This means that airlines operating only A380 aircraft will reduce their flight frequency, compared to the reference situation (null own ratio of A-380 use). However, the estimated coefficient for this dummy variable is generally insignificant in use of the A-380 when positive but lower than $100 \%$. This shows that there is no significant change in terms of flight frequency between airlines not using the A-380 and airlines using this aircraft for less than $100 \%$ of their traffic.

These results leads to the interesting conclusion that a very strong use of the A-380 drives down the frequency of flights and possibly lowers the level of $\mathrm{CO}_{2}$ emission.

When considering the innovation from competitors on the route, the estimations also provide interesting insights also. From the fixed effect model in column 1 of Table 2 we might falsely conclude that if the competitors increase their ratio of usage of A-380, the airline's own response is to reduce frequency. The first-differenced estimations show the opposite reaction following competitors' innovation. Under specifications 3 and 4, we see that company increases its frequency when competitors increase the intensity of A-380 use. The estimated coefficients are significant at the $10 \%$ level.

Spatial competition in airline industry - scheduled hours for the flight departures, could provide some insights for the positive sign of the coefficient of the competitors' ratio of A-380 use. The schedule of flights can be analyzed in the Hotelling framework with airline location on the 24-hour clock. Consumers are distributed not in terms of distance, but rather over time. The interpretation of the coefficient is that an increase in the competitors' ratio of total tonnes carried by the A-380 increases airline's own frequency of flight. The availability of additional hour on the flight schedule represents product differentiation in the airline market: there is a consumer, who values the availability of flight in a particular hour of day (Borenstein and Netz 1999). Thus, firms may have incentive to locate closer to competitors' time in order to capture marginal consumer demand. Our results show that airlines operating the A-380 on $100 \%$ of their traffic on a route tend to decrease their own frequency on this route. This in turn provides an additional free slot on the time-schedule, providing incentives for competitors on the route to increase their flight frequency in order to "steal" customers.

The other variables are dummies for month and year indicating that, in fact, the financial crisis in 2008, 2009 and 2010 led to a decrease in frequency of flights. The sign of the coefficients on monthly dummies indicate that there is a seasonal effect on frequency depending on summer or winter periods.

\section{Conclusion}

We analyze the impact on flight frequency of the use of the innovative aircraft A-380 on a route. Our model is a starting point in the empirical analysis of airlines' behavior and the environmental benefits that operation of the A-380 might potentially generate. Our results suggest that a very strong use of the large size aircraft A-380 leads airlines to reduce their frequency of flights. Besides, the use of the A-380 also by competitors on the route also has an impact on airline's flight frequency. Our results suggest that, when facing the introduction of the A-380 on a route, competitors will tend to react by increasing their own flight frequency. The next steps of this study will be to enhance the model by incorporating the fuel cost for all planes. We will also test instrumental variable and simultaneous equations approaches to tackle endogeneity caused by the interdependence of the strategic decisions of airline companies. This should allow us to better understand to what extent the A-380 can contribute to the evolution toward a more sustainable air transportation system.

\section{References}

Abeyratne, R. (2015). Competition and Investment in Air Transport: Legal and Economic Issues. en. GoogleBooks-ID: UCs3CwAAQBAJ. Springer. ISBN: 978-3-319-24372-6.

Aghion, P., Bechtold, S., Cassar, L., and Herz, H. (2014). The Causal Effects of Competition on Innovation: Experimental Evidence. 
Aghion, P., Bloom, N., Blundell R.and Griffith, R., and Howitt, P. (2002). Competition and Innovation: An Inverted U Relationship. Working Paper 9269. DOI: 10.3386/w9269. National Bureau of Economic Research. URL: http://www. nber.org/papers/w9269.

Babic, D., Kuljanin, J., and Kalic, M. (2014). "Market Share Modeling in Airline Industry: an Emerging Market Economic Application”. In: Transportation Research Procedia 3, pp. 384-392.

Baltagi, B.H (2008). Econometric analysis of panel data. Chichester, UK: John Wiley and Sons.

Bilotkach, V. (2014). "Parallel Frequent Flier Programme Partnerships: Impact on Frequency". In: Liberalization in Aviation 16, pp. 277-285.

Borenstein, S. and Netz, J. (1999). "Why do all the flights leave at 8 am?: Competition and departure-time differentiation in airline markets". In: International Journal of Industrial Organization 17, pp. 611-640.

Givoni, M. and Rietveld, P. (2009). “Airline's choice of aircraft size - Explanations and implications". In: Transportation Research Part A: Policy and Practice 43.5, pp. 500-510. ISSN: 0965-8564.

King, J.M. (2007). "The Airbus 380 and Boeing 787: A Role in the Recovery of the Airline Transport Market". In: Journal of Air Transport Management 13, pp. 16-22.

Miyoshi, C. and Mason, K.J. (2009). "The Carbon Emission of Selected Airlines and Aircraft Types in Three Geographic Markets”. In: Journal of Air Transport Management 15, pp. 138-147.

Morrell, P. (2009). "The Potential for European Aviation $\mathrm{CO}_{2}$ Emission Reduction through the Use of Larger Jet Aircraft”. In: Journal of Air Transport Management 15, pp. 151-157.

Pagovi, I. and Psaraki-Kalouptsidi, V. (2016). "The Impact of Carbon Emission Fees on Passenger Demand and Air Fares: A Game Theoretic Approach”. In: Journal of Air Transport Management 55, pp. 41-51.

Pai, V. (2010). “On the Factors that Affect Airline Flight Frequency and Aircraft Size”. In: Journal of Air Transport Management 16, pp. 169-177.

Park, Y. and O’Kelly, M. (2014). "Fuel Burn Rates of Commercial Passenger Aircraft: Variation by Seat Configuration and Stage Distance”. In: Journal of Transport Geography 41, pp. 137-147.

Scotti, D. and Volta, N. (2015). "An Empirical Assessment of the CO2-Sensitive Productivity of European airlines from 2000-2010”. In: Transportation Research Part D 37, pp. 137-149.

Wang, K., Gong, Q., Fu, X., and Fan, X. (2010). "Frequency and Aircraft Size Dynamics in a Concentrated Growth Market: The Case of the Chinese Domestic Market”. In: Journal of Air Transport Management 16, pp. 169177.

Wei, Y., Cui, Z., and Gil, M.J.A. (2016). “Assessing the Impact of Environmental Innovation in the Airline Industry: An Empirical Study of Emerging Market”. In: Environmental Innovation and Societal Transitions 10, pp. 1015 .

Wooldridge, J. (2006). Introductory Econometrics: a Modern Approach. Mason. 